\title{
Review of: "Multi-isotope evidence of population aggregation in the Natufian and scant migration during the early Neolithic of the Southern Levant"
}

\author{
Andrew Sillen ${ }^{1}$ \\ 1 Rutgers University
}

Potential competing interests: The author(s) declared that no potential competing interests exist.

Review of Santana, et al.

Multi-isotope evidence of population aggregation in the Natufian and scant migration during the early Neolithic of the Southern Levant.

I am writing this review shortly after the Washington Post ran a banner headline "A critical ocean system may be heading for collapse due to climate change, study finds." The last time the planet faced such a critical and rapid climate crisis related to oceanic conveyer-belt collapse was the Younger Dryas; a period, the authors note, which was concurrent in the Near East with the Late Natufian. This observation makes it apparent that archaeologists have a special obligation to study the impact of rapid climate change of the period, and the mechanism by which humans emerged from it with perhaps the most significant economic change in human history: the development of farming.

Santana et al. focus on the mechanism of population growth during the EpiPaleolithic/Neolithic transition, and seek to address the question using isotopic evidence; specifically they seek to distinguish population growth due to consolidation from that due to the demographic transition associated with sedentism. In many ways, this study is a step in the right direction; yet at best it presents a snapshot of the scientific state-of-the-art; the discourse could be improved by greater recognition of previous work in the region and beyond; by a full understanding of the limitations of their sampling strategy; and a look forward to much more resolved and useful information possibly available on the horizon.

With regard to past work, for one thing, the question of hunter-gatherer transhumance has been explored for the more recent past using isotopes in Southern Africa for over thirty years (notably by Judith Sealy, at the University of Cape Town); the authors would do well to consider this literature, as well as previous work in the Near East specifically at Ein Mallaha and other Natufian sites specifically on carbon isotopes. The authors appear to be unaware of previous research specifically connecting the Late Natufian to the Younger Dryas, and any possible implications of that. In 2021, as climate change accelerates due to the a mechanism similar to what occurred in the Younger Dryas, the significance of a comprehensive approach 
becomes all more salient and pressing.

I could not tell, from the text and appendices, whether the Ein Mallaha skeletons were Early, Late, or Final Natufian. That matters because nearly over 35 years ago I observed what appeared be a dietary perturbation in Late Natufian skeletons from Mallaha (Sillen, 1984; Sillen \& Lee Thorp; 1991; Sillen, 1991). To be sure, this work was on bone, which presents special challenges with regard to diagenesis; nevertheless there is at very least an indication that skeletal material throughout the Ein Mallaha sequence needs to be interpreted diachronically, and I could not construct a chronological sequence from these published data. I have in mind the experience of Kebara, where, upon radiocarbon dating, suspected Kebaran skeletons turned out to be, in fact, Natufian (Bar-Yosef and Sillen, 1993).

With regard to sampling strategy, the authors are correct to focus on dental enamel, since, as noted, bone from Near Eastern Epi-Paleolithic sites has been shown to have varying degrees of diagenesis, much of it fatal for paleodietary analysis. Yet the data collected on enamel is at best, a tantalizing glimpse into the potentially revelatory information these teeth contain. For one thing, different teeth calcify at different stages of growth; from fetal to adolescent; for another thing, each tooth is likely to contain a retrievable, interpretable record of both diet and locality; for first molars, some of the retrievable information is derived from maternal skeletons, and therefore relates directly to the movement of pregnant females (irrespective of the sex of the tooth) (Sillen \& Balter, 1997). Going forward, a methodical excavation of teeth, cognizant of dental microanatomy, would be especially useful for the detailed information they yet contain about life histories.

Therefore the study is useful for focusing on the value of isotopic analysis for Near Eastern archaeology. I believe the issues of transhumance the authors seek to address, and their bearing on the most important economic change in human history, are likely to be resolved using both isotopic and trace element methodologies, but only with the development of greater resolution-both in the chronology of the skeletons, and in the trace element and isotopic data they contain.

Refs:

https://www.washingtonpost.com/climate-environment/2021/08/05/change-ocean-collapse-atlanticmeridional/

Bar-Yosef, O. \& Sillen, A. (1993) Implications of the new accelerator date of the charred skeletons from Kebara Cave (Mt. Carmel). Paleorient 19/1 pp. 205-208.

Sillen A. \& Lee Thorp, J., (1991) "Dietary change in the Late Natufian" in Bar-Yosef, O. and F. Valla, (eds) The Natufian Culture in the Levant (pp.399-410). Ann Arbor, International Monographs in Prehistory. 
Sillen, A., (2002) Trace element and isotopic aspects of the origins of farming in the Levant. in R. Harrison \& R.M. Gillepsie, (eds. ) Eureka!! The Archaeology of Innovation \& Science (Proceedings of the 29th Annual Chacmool Conference, Calgary, Canada).

Sillen, A. \& Balter, V., (2018) Strontium isotopic aspects of Paranthropus robustus teeth; implications for habitat, residence, and growth, Journal of Human Evolution 114:118-130 